\title{
Fourier Transform-Ion Cyclotron Resonance Mass Spectrometric Resolution, Identification, and Screening of Non-Covalent Complexes of Hck Src Homology 2 Domain Receptor and Ligands from a 324-Member Peptide Combinatorial Library
}

\author{
Maria Wigger,* John R. Eyler, and Steven A. Benner \\ Department of Chemistry, University of Florida, Gainsville, Florida, USA \\ Weiqun $\mathrm{Li}^{\dagger}$ and Alan G. Marshall ${ }^{+}$ \\ Center for Interdisciplinary Magnetic Resonance, National High Magnetic Field Laboratory, Tallahassee, \\ Florida, USA
}

\begin{abstract}
The preferred ligands for the Hck Src homology 2 domain among a combinatorial library containing 324 different peptides were determined in a single experiment involving Fourier transform ion cyclotron resonance (FT-ICR) mass spectrometry (MS), electrospray ionization (ESI), stored-waveform inverse Fourier transformation (SWIFT), and infrared multiphoton laser disassociation (IRMPD). These were compared with the results obtained by conventional screening of the peptide library in solution using affinity chromatography. The results reported here show that by combining ESI, FT-ICR MS, SWIFT, and IRMPD, ligands likely to bind under physiological conditions are rapidly and efficiently identified, even from complex library mixtures. In the gas phase some discrimination against hydrophobic ligands could be observed. However, the illustrated feasibility of identifying high affinity ligand via gas-phase screening of complex library mixtures should lead to broad applications in the development of ligands for proteins with interesting biological activity, the first step that must be taken to develop a therapeutic agent. (J Am Soc Mass Spectrom 2002, 13, 1162-1169) () 2002 American Society for Mass Spectrometry
\end{abstract}

A variety of innovations has permitted mass spectrometry (MS) to expand its scope beyond small organic molecules to encompass biological macromolecules, including proteins and nucleic acids $[1,2]$. Fourier transform ion cyclotron resonance (FT-ICR) mass adds unique features to the possibilities of mass spectrometric characterization of biomolecules [3]. It allows the observation of ions of high molecular weight proteins at ultra high resolution and high mass accuracy.

Important in the application of FT-ICR methods to biological macromolecules are "soft" ionization techniques, which generate macromolecular ions without

Published online August 22, 2002

Address reprint requests to Dr. S. A. Benner, Department of Chemistry, University of Florida, Gainesville, FL 32611-7200, USA. E-mail: benner@chem.ufl.edu

*Also at the Department of Chemistry, Swiss Federal Institute of Technology, CH-8092 Zürich, Switzerland.

${ }^{\dagger}$ Department of Chemistry, Florida State University, Tallahassee, FL 323064390 . fragmentation. Electrospray ionization (ESI) and matrix-assisted laser desorption/ionization (MALDI) are two of these $[4,5]$. ESI involves spraying an aqueous solution of a biological macromolecule under "quasiphysiological" conditions directly into a mass spectrometer. The solvent evaporates in the vacuum from the droplets, gently "elevating" a biological ion from its native environment in solution. This process frequently leaves non-covalent macromolecular complexes intact and allows the mass spectrometric observation of enzyme-substrate, receptor-ligand, peptide-peptide, protein-subunit, oligonucleotide-toxin/drug, and DNA duplex binding in the gas phase [6].

In many cases, binding constants estimated from mass spectrometric studies match the binding constants obtained in solution to within an order of magnitude [7]. The gentleness of ESI allows H/D exchange experiments in the gas phase to give information about protein conformation and protein/protein interactions based on measurements of the exchange rates of protein backbone amide protons [8,9]. This combination of 
delicate handling of sensitive biological macromolecules and high resolution mass spectrometry now has the potential to yield insight into ongoing biological activity $[10,11]$.

ESI combined with FT-ICR MS might be applied to detect complexes between biological macromolecules and ligands selected from a library of smaller organic molecules. In principle, the complex between the macromolecular receptor and the preferred ligand can be detected directly by FT-ICR MS, and a single experiment can determine the mass of the molecule that has the highest affinity for the receptor from a (potentially) large number of small organic molecules. If the ligand can be subsequently released from the complex and itself analyzed by mass spectrometry, it might be possible to determine the structure of the tightest ligand for a receptor from a library of candidate receptors without the need of solution-phase separation procedures. Nonspecific binding should be less problematic when using ligand mixtures [7], because competitive-binding conditions are an intrinsic property of combinatorial library screening and high-affinity ligands are expected to displace low-affinity ligands from the binding pocket (when present in comparable amounts).

A pilot demonstration of the screening of a highly degenerate combinatorial library by isolation and identification of non-covalent complexes in the gas phase has been published [12]. Nevertheless, the limitations of the mass spectrometric technique are not yet well defined, and comparison of solution phase and gasphase protein structure and reactivity has just begun [13]. The value of such an approach to the development of pharmaceutical agents is apparent.

We report here an implementation of this approach to identify the preferred ligands for Src homology 2 (SH2) domains. SH2 domains are non-catalytic polypeptides $\sim 100$ amino acids in length. They were originally defined in the Src family of phosphotyrosine kinases, and disturbance of the complex signaling cascades severely affects principal cellular functions. Alteration or loss of the function of an SH2 domain is frequently associated with cell transformation and cancer.

$\mathrm{SH} 2$ domains are found as modules in a variety of proteins, including phospholipase C- $\gamma$, GTPase activating protein, phosphatidylinositol 3'-kinase, and many other systems involved in signal transduction pathways [14]. Their primary binding specificity is to phosphorylated tyrosine. Different SH2 domains have differing specificities for the surrounding peptide sequence, however, and this secondary binding specificity is responsible for the distinctive biological properties of each SH2 domain $[15,16]$.

The hematopoietic cell kinase (Hck) SH2 domain is a member of the Src SH2 subfamily of cellular tyrosine kinases $[17,18]$. It is preferentially expressed in myeloid and B-lymphoid cells and is bound to B-cell receptors in unstimulated B cell lineages. Recent studies on Hck SH2 domain suggested a new role for $\mathrm{SH} 2$ domains as intramolecular positioning tools for $\mathrm{SH} 3$ domains and entailed a reevaluation of the importance of $\mathrm{SH} 2$ and $\mathrm{SH} 3$ domains in the process of intermolecular signal transduction $[19,20]$.

Here, we report the screening of Hck SH2 domain with a 324-member combinatorial peptide library using gas phase screening via non-covalent complex formation in comparison with conventional affinity-based screening, which has not been done to date with a library of this size. The non-covalent complexes between this SH2 domain and the preferred phosphopeptide ligands were identified by use of the ESI technique to generate ions, FT-ICR MS joined with the stored-waveform inverse Fourier transform (SWIFT) technique to trap and isolate the non-covalent complex, and subsequent IRMPD-irradiation to release the preferred binding ligands [21, 22]. We then compare and discuss the gas-phase results in terms of those derived from conventional screening assays.

\section{Experimental}

\section{Synthesis of a Degenerate Peptide Library}

A peptide library having the general formula Ac-GpYEXX-ethylenediamine (Eda) (where X is any of 18 amino acids), was synthesized on diaminoethanetrityl resin (345 $\mathrm{mg}, 0.1 \mathrm{mmol}$ ) (Novabiochem) by use of the Fmoc/tBu orthogonal protection strategy and standard $\mathrm{HBTU} / \mathrm{HOBt} / \mathrm{DIEA}$ activation procedure with piperidine deprotection [23-26]. Yields were ca. 90\%. The degenerate positions, indicated by " $\mathrm{X}$ " in the general sequence, were synthesized by successive coupling of an equimolar mixture ("cocktail") of protected Fmoc amino acids by means of the "mixture coupling approach" described elsewhere and the above standard solid-phase peptide synthesis protocols [27]. The Fmoc amino acid cocktail was made by dissolving the (eighteen) weighed amino acids, FmocAlaOH, FmocArg(Pbf) $\mathrm{OH}$, FmocAsn(Trt)OH, FmocAsp(tBu)OH, FmocGln(Trt)OH, FmocGlu(tBu)OH, FmocGlyOH, FmocHis (Trt)OH, FmoclleOH, FmocLys(Boc)OH, FmocPheOH, FmocSer(tBu)OH, FmocThr(tBu)OH, FmocTrp(Boc)OH, FmocTyr(tBu)OH, FmocValOH, FmocProOH, and Fmoc$\mathrm{MetOH}$, in DMF to a final concentration of $0.2 \mathrm{mmol} / \mathrm{mL}$. Cys and Leu were omitted from the cocktail, for a total library of $18 \times 18=324$ peptides.

After the two degenerate amino acids were coupled to the resin, FmocGlu(OtBu)OH ( $255 \mathrm{mg}, 0.6 \mathrm{mmol}$ ) was coupled to $\mathrm{H}-\mathrm{Xxx}$-Xxx-diaminoethane-trityl-resin by the standard procedure. Phosphotyrosine was introduced as FmocTyr $\left(\mathrm{PO}_{3} \mathrm{Me}_{2}\right) \mathrm{OH}(194 \mathrm{mg}, 0.3 \mathrm{mmol})$ in an analogous fashion. After removal of the terminal Fmoc group, AcGlyOH (70 mg, $0.6 \mathrm{mmol})$ was coupled to the amino-terminus by use of the activation procedure described above. The resin was dried and deprotected with TMSBr $(1.5 \mathrm{~mL}, 10 \mathrm{mmol})$ in TFA/EDT/ TA/TIS (92.5:2.5:2.5:2.5, $10 \mathrm{~mL}$ ) by incubation for $5 \mathrm{~h}$ under Ar. The peptide library was precipitated with 
diethyl ether, redissolved in $\mathrm{NH}_{4} \mathrm{HCO}_{3}(0.1 \mathrm{M})$ and lyophilized to yield the crude peptide library $(123 \mathrm{mg})$ as a white solid.

\section{Preparation of Hck SH2 Domain for Non-Covalent Binding Studies}

The Hck SH2 domain (henceforth denoted as M) stock ( $9 \mathrm{mg} / \mathrm{mL}, 2 \mathrm{mM}$ DTT, $0.02 \% \mathrm{NaN}_{3}$, Novartis Pharmaceuticals, Basel, Switzerland) was desalted on Sephadex PD10 columns (Pharmacia, Piscataway, NJ) that had been equilibrated in degassed, ice-cold, deionized water. After addition of DTT $\left(1 \mathrm{M}\right.$ in $\left.\mathrm{H}_{2} \mathrm{O}\right)$ to a final concentration of $3 \mathrm{mM}$, aliquots of the protein were used immediately or stored at $-20^{\circ} \mathrm{C}$.

\section{Non-Covalent Binding of Library to Receptor}

The peptide library, Ac-GpYEXX-Eda (0.5 mg, 2 nmole per single peptide), henceforth denoted as L, was dissolved in deionized water and added to $1.6 \mathrm{nmol}$ of protein to give a final volume of $300 \mu \mathrm{L}$. The mixture was incubated at room temperature for $3 \mathrm{~h}$, chilled on ice and concentrated by MicroCon (St. Louis, MO) 10 to a final volume of $20 \mu \mathrm{L}$ at $4{ }^{\circ} \mathrm{C}$. The protein/library mixture was diluted with $150 \mu \mathrm{L} \mathrm{H}_{2} \mathrm{O}$. Non-covalent complex formation was detected at a flow rate of 0.1-1 $\mu \mathrm{L} / \mathrm{min}$ in a $9.4 \mathrm{~T}$ ESI FT-ICR mass spectrometer [28, 29]. Flow rates of 0.3 to $0.5 \mathrm{~mL} / \mathrm{min}$ were found to be optimal for the detection of non-covalent complexes using this instrument, although this varied from day to day. The parameters of the ESI source and the ion optics were adjusted for maximum signal for the non-covalent complex. In general, an octopole accumulation period of $8 \mathrm{~s}$ was found to give the highest signal for the non-covalent complex.

\section{SWIFT Isolation and Laser-Induced Ligand Release}

The multiply-charged ligand:receptor complexes $[\mathrm{M}+$ $\left.\mathrm{L}+11 \mathrm{H}^{+}\right]$, were isolated by the SWIFT technique [21, 22]. A Synrad carbon dioxide IR laser (SYNRAD Inc., Mukilteo, WA) beam was used to dissociate each noncovalent complex to release its bound ligand. The laser power was high enough to achieve near-complete removal of non-covalent complexes but low enough to avoid peptide or protein fragmentation.

\section{Immobilization of Hck on a Solid Support}

Hck SH2 domain $(0.5 \mathrm{~mL}, 4.5 \mathrm{mg})$ dissolved in $2 \mathrm{mM}$ DTT, $0.02 \% \mathrm{NaN}_{3}$ was purified over a Sephadex PD10 column that was preequilibrated in sodium phosphate (100 mM, pH 7). The protein-containing fractions were combined and immobilized on preactivated agarose Affi-Gel 10 (BioRad, Hercules, CA) $(4 \mathrm{~mL})$ at $4{ }^{\circ} \mathrm{C}$ for $5 \mathrm{~h}$ according to the manufacturer's instructions. A coupling rate of $4 \mathrm{mg}$ Hck SH2 domain per $4 \mathrm{~mL}$ gel (67.7 $\mathrm{nmol}$ protein $/ \mathrm{mL}$ gel) was determined by measuring the free protein in solution based on a Bradford assay [30]. Excess activated esters were blocked by addition of ethanolamine (1 M, pH 8, $0.1 \mathrm{~mL})$. The resin was rinsed thoroughly in sodium phosphate buffer $(0.1 \mathrm{M})$ containing EDTA ( $2 \mathrm{mM})$, DTT $(2 \mathrm{mM})$, and $\mathrm{NaN}_{3}(0.02 \%)$ and stored at $4{ }^{\circ} \mathrm{C}$ until use. For the negative controls, the resin was treated as for the protein immobilization procedure but with ethanolamine $(1 \mathrm{M}, 0.2 \mathrm{~mL})$ instead of protein.

\section{Affinity Screening of Hck SH2 Domain}

The refrigerated Hck SH2 domain on agarose $(100 \mu \mathrm{L})$ was washed five times with ice-cold $\mathrm{NH}_{4} \mathrm{OAc}(0.1 \mathrm{M}, 1$ $\mathrm{mL}$ ) buffer. The agarose was sedimented by gentle centrifugation and the supernatant was removed after each washing step. Ac-GpYEXX-Eda $(0.048 \mathrm{mg}-0.24 \mathrm{mg}$, 0.2-1 nmol of each compound) was added to the desalted Hck SH2 agarose and made up to a final volume of $300 \mu \mathrm{L}$ with $\mathrm{NH}_{4} \mathrm{OAc}(0.1 \mathrm{M}, \mathrm{pH}$ 7.5). The Hck SH2 domain agarose/library mixture was incubated for $3 \mathrm{~h}$ at room temperature and then chilled on ice. The incubation mixture was transferred to a MicroPure Separator (Amicon, Danvers, MA) and centrifuged for $2 \mathrm{~s}$ to remove excess solvent. Ice-cold $\mathrm{NH}_{4} \mathrm{OAc}(0.1 \mathrm{M}$, $\mathrm{pH}$ 7.5) was added to the moist agarose gel and centrifuged for $2 \mathrm{~s}$ as above. This washing step was performed four times. The wash solutions were collected separately. The tightly bound peptides were eluted with $4 \times 300 \mu \mathrm{L} \mathrm{HCOOH}(0.1 \%)$ at RT. The elution fractions were lyophilized, then redissolved in $\mathrm{HCOOH}(0.1 \%) / \mathrm{MeOH}$ (50:50) for ESI FTICR MS analysis. The negative control was performed analogously on the deactivated agarose.

\section{CID-Fragmentation of High-Affinity Ligands}

The high-affinity ligand solution was infused at a flow rate of $0.5-3 \mu \mathrm{L} / \mathrm{min}$ into an ion trap quadrupole mass spectrometer (LC-Q, Finnigan, San Jose, CA) equipped with an ESI-ion source. The ligand ions were isolated within an $\mathrm{m} / \mathrm{z}$ window of $\pm 1-2$ and fragmented by applying a voltage of 25-30 V depending on the ease of fragmentation of the individual ions.

\section{Results and Discussion}

We recently reported the use of ESI FT-ICR mass spectrometry as a tool to analyze highly degenerate libraries of compounds [31], and showed how it can be applied to the real time monitoring of substrate library screening by enzymes [11]. However, many biological processes can be triggered simply by non-covalent binding of a ligand to a target biomolecule without any further covalent modification. The gentle ionization provided by ESI has the potential to allow direct observation of this non-covalent complex in the gas phase in a mass spectrometer, and ultimately allow the 


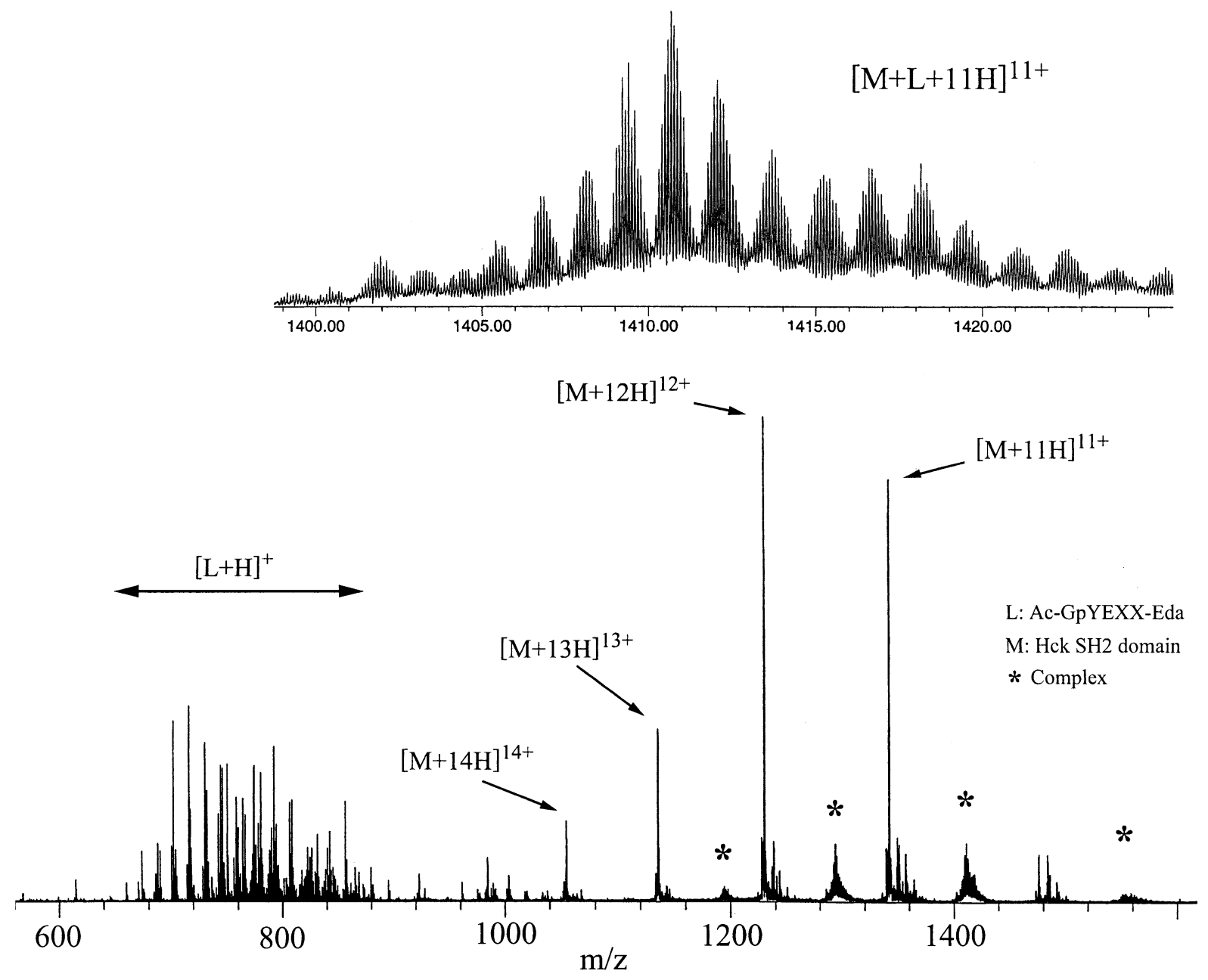

Figure 1. Fourier transform ion cyclotron resonance (FT-ICR, 9.4 Tesla) mass spectrum of Hck SH2 domain, electrospray-ionized from a solution containing the complete library, $\mathrm{L}=$ Ac-GpYEXX-Eda. Inset: Mass scale expansion showing resolution of various tightly bound non-covalent complexes $[\mathrm{M}+\mathrm{L}+11 \mathrm{H}]^{+11}$.

identification of a few preferred ligands from a highly degenerate combinatorial library. For example, Gao et al. used ESI FT-ICR MS to determine the components of a library of 289 sulfonamide-derivatized peptides that bound most strongly to carbonic anhydrase [12]. Here, we report the detection and characterization of the binding specificities of Hck $\mathrm{SH} 2$ domain protein to a compound library of 324 phosphorylated peptides by ESI FT-ICR mass spectrometry, and compare it to the results of solution screening.

\section{Non-Covalent Binding}

The Hck SH2 domain forms non-covalent complexes Figure 1, (bottom) with members of a peptide library having the general sequence, Ac-GpYEXX-Eda. The library had a maximum of 324 compounds synthesized by the "mixture coupling" approach. Each component of the library was acetylated at the $\mathrm{N}$-terminus and modified by ethylenediamine at the C-terminus. $\mathrm{X}$ represents any of the 20 amino acids except Cys and
Leu. Cys was omitted to exclude the possibility of disulfide formations, whereas Leu was omitted to avoid confusion in binding of Ile- versus Leu-containing peptides due to their identical mass.

Comparison of many libraries previously synthesized by this approach with simulated library mass spectra showed that these peptide libraries were correctly obtained with expected degeneracy (data not shown). The preconcentration step reduces the total salt/library content of the mixture. It may also help compensate for the slightly different concentrations of the single compounds in the library caused by different coupling efficiencies (see below).

As shown in the mass scale-expansion in Figure 1 (top), the multiply-charged non-covalent complex, $\left[\mathrm{M}+\mathrm{L}+11 \mathrm{H}^{+}\right]^{11+}$, shows a rather broad mass distribution containing several overlapped non-covalent complexes of Hck SH2 domain with each of several strongly bound ligands. The identities of these ligands in the complexes could in principle be obtained from the accurate masses of the complexes. However, such 


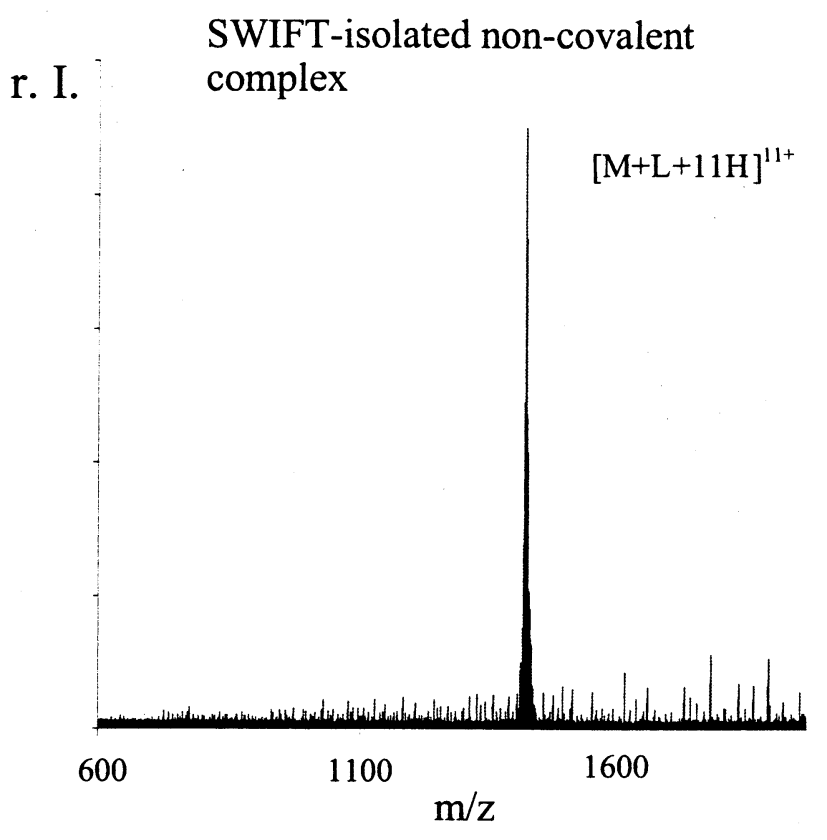

Figure 2. FT-ICR mass spectrum of SWIFT-isolated multiplycharged non-covalent complexes, $\left[\mathrm{M}+\mathrm{L}+11 \mathrm{H}^{+}\right]^{+11}$, between Hck SH2 domain and members of the peptide ligand library, $\mathrm{L}=$ Ac-GpYEXX-Eda. Note that the expanded spectrum looks the same as in Figure 1. identification is rendered difficult by overlap of the isotopic distributions of different complexes, as well as the presence of adducts (e.g., $\mathrm{Na}^{+}, \mathrm{K}^{+}$in place of $\mathrm{H}^{+}$) which further broadens each isotopic distribution [7].

Therefore, a simpler means for identifying the strongly bound ligands was developed. The complexes of interest were first isolated using the SWIFT technique $[21,22]$. This technique ejects from the Penning ion trap all ions having $\mathrm{m} / \mathrm{z}$ different from that of the complex of interest (Figure 2). The isolated $\left[\mathrm{M}+\mathrm{L}+11 \mathrm{H}^{+}\right]^{11+}$ complexes may then be dissociated by IRMPD by use of continuous wave (CW) IR laser irradiation. This procedure yields free intact $\mathrm{SH} 2$ domain protein, $[\mathrm{M}+$ $\left.10 \mathrm{H}^{+}\right]^{10+}$, and the ligand(s) released from the complex, $\mathrm{L}^{+}$Figure 3, (bottom). The laser power was adjusted to achieve maximum dissociation of the non-covalent complex without fragmentation of the peptides or protein. The signal intensity of residual complex at this point was less than $10 \%$ of the starting signal intensity. The mass scale expansion in Figure 3 (top right) shows the intact free protein, $\left[\mathrm{M}+10 \mathrm{H}^{+}\right]^{10+}$, whereas Figure 3 (top left) shows the released singly-charged library molecules with good signal-to-noise ratio and exquisite mass resolution.

With the Hck $\mathrm{SH} 2$ domain, two major peaks $(\mathrm{m} / \mathrm{z}$ 760.3 and 774.3) were obtained. These species were at least twice as abundant as any of the other released

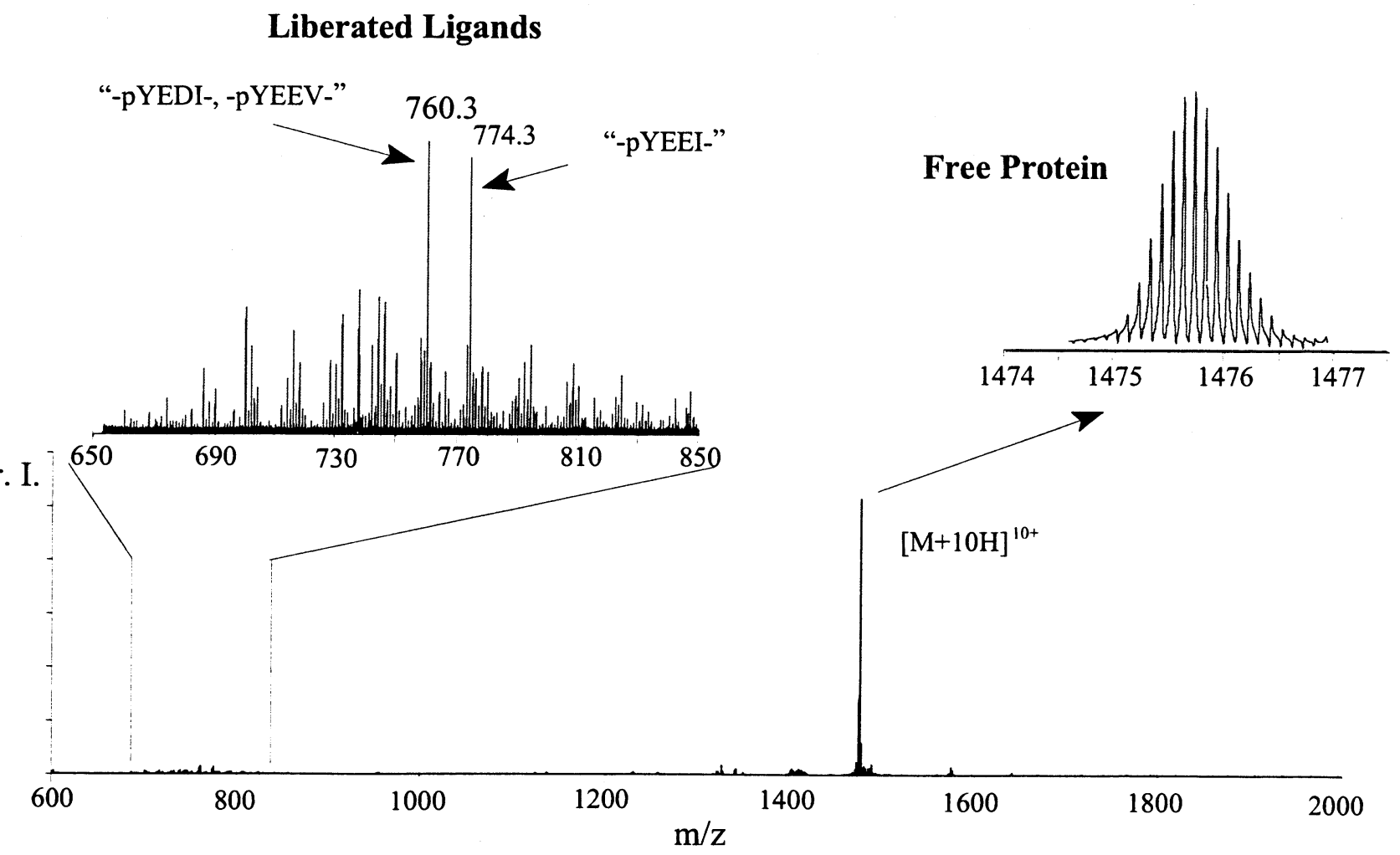

Figure 3. FT-ICR mass spectrum following infrared multiphoton dissociation of tightly-bound non-covalent complexes, $\left[\mathrm{M}+\mathrm{L}+11 \mathrm{H}^{+}\right]^{+11}$, to yield free Hck SH2 domain $(10+$ charge state) and its (singly-charged) ligands. The insets show mass scale-expanded segments for the released ligands (upper left) and the isotopically resolved free protein $[\mathrm{M}+10 \mathrm{H}]^{+11}$ (upper right). The two major peaks correspond to the peptides, Ac-GpYEXX-Eda, in which XX = DI/EV or EI, respectively. 
library components. They were assigned by their mass to two of the library components, pYEDI/pYEEV and pYEEI, respectively. The latter is known to be the highest affinity binding sequence for the Src SH2 domain [15], a close evolutionary relative of the Hck $\mathrm{SH} 2$ domain. In these studies the binding motif $\mathrm{pYE}(\mathrm{E}$, $\mathrm{D})(\mathrm{I}, \mathrm{V}, \mathrm{M})$ was identified for the closest relative to Hck $\mathrm{SH} 2$, the Lck SH2 domain. Due to the relatively small number of released ligand ions, further IRMPD fragmentation of these ligands was not attempted.

\section{Affinity Screening}

To compare the results obtained by the mass spectrometric method with those obtained from a conventional library screening protocol, the 324-compound library Ac-GpYEXX-Eda 1 ( $\sim 0.1 \mathrm{nmol}$ for each compound) was presented to Hck $\mathrm{SH} 2$ domain immobilized onto agarose. The affinity screening of Hck $\mathrm{SH} 2$ on agarosesupport allows for fast removal of excess library $(<10 \mathrm{~s})$ with minimal loss of tight-binding ligands, something of concern given the short half lives of the complexes between other $\mathrm{SH} 2$ domains and their preferred peptide ligand [32]. An agarose support was chosen for its hydrophilicity, which minimizes protein distortions and lowers the amount of non-specific binding. After a wash with ice-cold buffer to remove excess library and low affinity ligands, high-affinity ligands were eluted with $0.1 \%$ formic acid. The final acid elution showed $\sim 10$ distinct mass spectral peaks. Two independent screenings showed the same mass spectral peaks from the final elution. The peak magnitudes of the acidelutions in both experiments did not deviate more than $\sim 10 \%$. The elution fractions were lyophilized, redissolved, and analyzed by ESI FTICR MS (4.7 T). The mass spectra of the first washing solution (which represents the excess unbound library) and the final elution fraction are illustrated in Figure 4 (top and middle), respectively.

A negative control with deactivated Affi-Gel 10 was performed analogously. The deactivated agarose gel was obtained by quenching activated ester positions with excess ethanolamine during the coupling. The acid-elution of the negative control Figure 4, (bottom) shows two major peaks that corresponded to two major peaks in the Hck SH2 domain screening. The slightly higher masses already indicated the non-peptidic origin of these mass peaks, as later confirmed by CID fragmentation. Non-peptidic contaminants as identified via CID-fragmentation are marked with an asterisk.

All ions generating a signal of sufficient magnitude were subjected to CID fragmentation. Due to low ligand concentration, the amino acid sequence determination was performed with an LC-Q ion trap mass spectrometer that allows CID fragmentation of multiple ions in a short period of time. The same tight-binding ligands were identified in a solution screening assay by use of ultrafiltration devices (MicroCon 10) (data not shown).
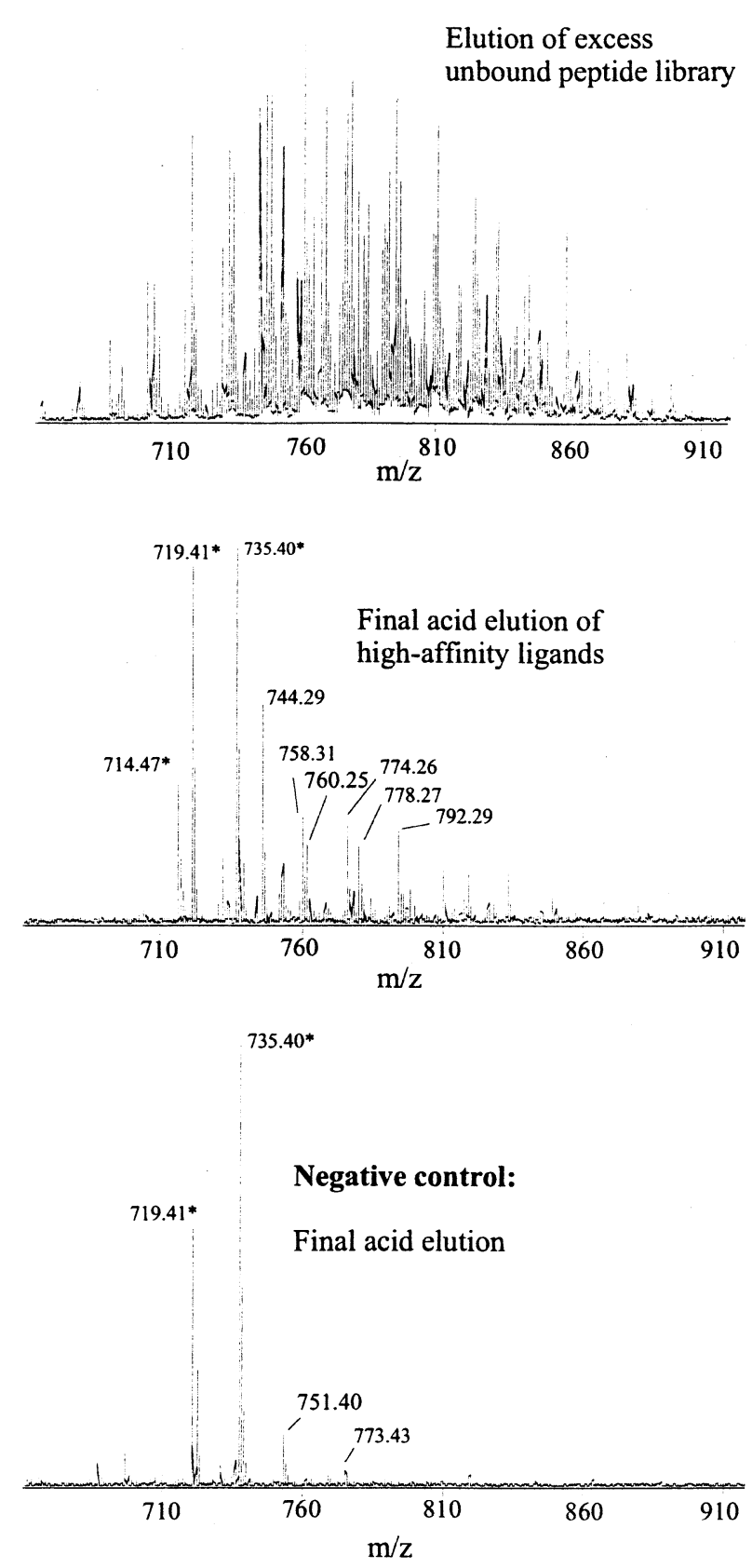

Figure 4. FT-ICR mass spectra (4.7 tesla), showing resolution of unbound (top) and tightly-bound (bottom) Ac-GpYEXX-Eda ligands in the affinity-screening by immobilized Hck SH2 domain. Top: First elution of unbound and loosely bound library ligands. Middle: Final acid elution of tightly-bound ligands. Bottom: Final acid elution of the negative control (asterisk denotes artifact peaks).

The results of CID fragmentation are summarized in Table 1.

The elucidated sequences reveal two major amino acid binding motifs for Hck SH2 domain. The first had a phosphotyrosine followed by a glutamate, and then two hydrophobic residues. Isoleucine and valine were preferred as the hydrophobic amino acids in the $\mathrm{pY}+3$ position. The second motif had a phosphotyrosine followed by a glutamate, followed by either a glutamate or 
Table 1. High-affinity ligands detected by ESI-MS and CID fragmentation

\begin{tabular}{|c|c|c|}
\hline$[\mathrm{M}+\mathrm{H}]^{+}$ & $\begin{array}{c}\text { Relative } \\
\text { Abundance }\end{array}$ & $\begin{array}{c}\text { Sequence Assignment } \\
\text { Ac-GpYEXX-Eda }\end{array}$ \\
\hline $714.47 \mathrm{Da}^{\mathrm{a}}$ & $++^{b}$ & Non-peptidic contaminant \\
\hline 719.41 & $+++^{d}$ & Non-peptidic contaminant \\
\hline 730.31 & + & $-\mathrm{V}-\mathrm{V}-$ \\
\hline 735.40 & +++ & Non-peptidic contaminant \\
\hline 744.34 & $++^{\mathrm{c}}$ & -V-I-(65\%); -I-V-(35\%) \\
\hline 758.35 & + & $-1-1$ \\
\hline 760.29 & + & -D-I- $(50 \%) ;-$-V-V-(50\%) \\
\hline 774.30 & + & -E-I- \\
\hline 778.31 & + & $-F-V-$ \\
\hline 792.34 & + & -F-I-(70\%); -I-F-(30\%) \\
\hline
\end{tabular}

aPrecision mass measurement $\pm 0.01 \mathrm{Da}$

${ }^{b}$ Relative abundance low.

'Relative abundance medium.

${ }^{\mathrm{d}}$ Relative abundance high.

an aspartate, followed by either an isoleucine or a valine. The second motif corresponds directly to the sequence identified from the non-covalent binding studies in the gas phase, and is consistent with the expectation based on the close evolutionary relationship between Hck, Lck, and Src SH2 domains.

The observation of tight binding amino acid motifs carrying a hydrophobic amino acid at the pY +2 position is consistent with results of studies in solution reported by Payne et al. [33]. In these studies, replacement of Glu at pY +2 with hydrophobic amino acids such as Ile resulted in negligibly different binding constants to Lck. In the crystal structure of Hck SH2 domain, the $\mathrm{pY}+2$ residue projects away from the protein toward the solvent and therefore plays a less important role for the binding.

Our inability to observe the binding motif pY-Ehydrophobic-hydrophobic during the non-covalent binding studies in the gas phase matches recent results by Smith and coworkers, who quantitated and compared gas phase stabilities of carbonic anhydrase complexed with some of its known inhibitors with hydrophobicity and the calculated polar surface areas of these selected ligands [13]. Their comparison indicated that polar interactions are the dominating forces for protein/ligand interactions in the gas phase, whereas hydrophobic interactions determine the binding strength in solution. As a consequence, hydrophobic ligand receptor interactions are less likely to be observed in the gas phase, consistent with the results reported here.

Last, we must consider the possibility that the solid phase peptide synthesis generated a library that was very biased, that different peptides were represented in very different amounts, and that the peptides identified in this experiment were simply those present in large amounts in the original library. Several observations make this less than likely. First, the spectrum of the peptide library itself shows no large differences in peptides present in the mixture, and no evidence for dramatically different detection of different peptides in the mixture. If the peptides identified in the experiment were simply the compounds that had the highest concentrations in the library, then one would expect an intense mass peak at the corresponding $\mathrm{m} / \mathrm{z}$ of the mass spectrum of the peptide mixture. No such peak is seen (see the lower mass region of Figure 1). To rule out very different detection mass spectrum detection responses, we simulated the ion mass distribution in the library (assuming equal coupling efficiencies in the peptide synthesis), and compared it to the actual distribution of masses in the MS of the peptide library. The two corresponded closely, indicating both that the distribution of peptides in the mixture was not very different from that expected with equal coupling efficiencies, and that the detectability of different peptides was nearly uniform.

One way to have a "less preferred" peptide emerge from this experiment is if its total stoichiometry is less than the stoichiometry of the receptor. The preconcentration step, in addition to removing salt, ensured that even if the peptide was inefficiently synthesized (present at only $10 \%$ of the concentration of the average peptide), then it would still be present in sufficient stoichiometric amounts to saturate the receptor.

\section{Conclusion}

The results reported here illustrate the range of biological questions relating to protein ligand interactions that might be addressed by combining ESI, FT-ICR MS, SWIFT, and IRMPD [34]. Although we observed discrimination against hydrophobic interactions in transferring the non-covalent receptor/ligand complexes from solution to the gas phase, the gas phase screening technique allowed the identification of the same high affinity ligands as far as polar ligands are concerned. Moreover, the speed and simplicity of the mass spectrometric non-covalent binding assay makes it preferable to solution methods for efficient screening of large combinatorial libraries. Only 1-2 nmol of protein are needed for an experiment. No preparative isolation of the protein/ligand complex is required. The analysis can be done under quasi-physiological conditions, directly from the incubated protein/library mixture. Finally, CID fragmentation of ligands released and isolated in the gas phase can unequivocally establish the chemical structure of each preferred ligand. Thus, incubation, selection, and structure determination can effectively be done in a single analysis.

\section{Acknowledgments}

The authors thank Dr. David H. Powell and Dr. Jodie V. Johnson for their help and access to the LC-Q mass spectrometer at the University of Florida. They are indebted to Dr. Goetz Baumann (Novartis Pharmaceuticals) for a gift of the Hck SH2 domain protein, and to the NIH (GM 54048, GM 54075, and GM 31683), the NSF (CHE 94-13008) and National High Magnetic Field Laboratory In-House Research Program for partial support of this work. 


\section{References}

1. Shevchenko, A.; Jensen, O. N.; Podtelejnikov, A. V.; Sagliocco, F.; Wilm, M.; Vorm, O.; Mortensen, P.; Shevchenko, A.; Boucherie, H.; Mann, M. Linking Genome and Proteome by Mass Spectrometry: Large-Scale Identification of Yeast Proteins from Two Dimensional Gels. Proc. Nat. Acad. Sci. U.S.A. 1996, 93, 14440-14445.

2. Link, A. J.; Hays, L. G.; Carmack, E. B.; Yates, J. R. Identifying the Major Proteome Components of Haemophilus influenzae Type Strain NCTC 8143. Electrophoresis 1997, 8, 1314-1334.

3. Marshall, A. G.; Hendrickson, C. L.; Jackson, G. S. Fourier Transform Ion Cyclotron Resonance Mass Spectrometry: A primer. Mass Spectrom. Rev. 1998, 17, 1-35.

4. Fenn, J. B.; Mann, M.; Meng, C. K.; Wong, S. F. Electrospray Ionization-Principles and Practice. Mass Spectrom. Rev. 1990, 9, 37-70.

5. Karas, M.; Hillenkamp, F. Laser Desorption Ionization of Proteins with Molecular Masses Exceeding 10,000 daltons. Anal. Chem. 1988, 60, 2301-2303.

6. Smith, R. D.; Bruce, J. E.; Wu, Q.; Lei, Q. P. New Mass Spectrometric Methods for the Study of Noncovalent Associations of Biopolymers. Chem. Soc. Rev. 1997, 26, 191-202.

7. Loo, J. A.; Hu, P. F.; McConnell, P.; Mueller, W. T.; Sawyer, T. K.; Thanabal, V. A Study of Src SH2 Domain ProteinPhosphopeptide Binding Interactions by Electrospray Ionization Mass Spectrometry. J. Am. Soc. Mass Spectrom. 1997, 8, 234-243.

8. Wood, T. D.; Chorush, R. A.; Wampler, F. M.; Little, D. P.; O'Connor, P. B.; McLafferty, F. W. Gas-Phase Folding and Unfolding of Cytochrome-C Cations. Proc. Nat. Acad. Sci. U.S.A. 1995, 92, 2451-2454.

9. Anderegg, R. J.; Wagner, D. S. Mass-Spectrometric Characterization of a Protein Ligand Interaction. J. Am. Chem. Soc. 1995, 117, 1374-1377.

10. Smith, R. D.; Loo, J. A.; Edmonds, C. G.; Barinaga, C. J.; Udseth, H. R. NEW Developments in Biochemical Mass-Spectrometry-Electrospray Ionization. Anal. Chem. 1990, 62, 882899.

11. Wigger, M.; Nawrocki, J. P.; Watson, C. H.; Eyler, J. R.; Benner, S. A. Assessing Enzyme Substrate Specificity Using Combinatorial Libraries and Electrospray Ionization Fourier Transform Ion Cyclotron Resonance Mass Spectrometry. Rapid Commun. Mass Spectrom. 1997, 11, 1749-1752.

12. Gao, J.; Cheng, X.; Chen, R.; Sigal, G. B.; Bruce, J. E.; Schwartz, B. L.; Hofstadler, S. A.; Anderson, G. A.; Smith, R. D.; Whitesides, G. M. Screening Derivatized Peptide Libraries for Tight Binding Inhibitors to Carbonic Anhydrase II by Electrospray Ionization Mass Spectrometry. J. Med. Chem. 1996, 39, 1949-1955.

13. Wu, Q.; Gao, J.; Joseph-McCarthy, D.; Sigal, G. B.; Bruce, J. E.; Whitesides, G. M.; Smith, R. D. Carbonic Anhydrase-Inhibitor Binding: From Solution to the Gas Phase. J. Am. Chem. Soc. 1997, 119, 1157-1158.

14. Koch, C. A.; Anderson, D.; Moran, M. F.; Ellis, C.; Pawson, T. $\mathrm{SH} 2$ and SH3 Domains-Elements that control interactions of cytoplasmic signaling proteins. Science 1991, 252, 668-674.

15. Songyang, Z.; Shoelson, S. E.; Chaudhuri, M.; Gish, G.; Pawson, T.; Haser, W. G.; King, F.; Roberts, T.; Ratnofsky, S.; Lechleider, R. J.; Neel, B. G.; Birge, R. B.; Fajardo, J. E.; Chou, M. M.; Hanafusa, H.; Schaffhausen, B.; Cantley, L. C. SH2 Domains Recognize Specific Phosphopeptide Sequences. Cell 1993, 72, 767-778.

16. Songyang, Z.; Shoelson, S. E.; Mcclade, J.; Olivier, P.; Pawson, T.; Bustelo, X. R.; Barbacid, M.; Sabe, H.; Hanafusa, H.; Yi, T.; Ren, R.; Baltimore, D.; Ratnofsky, S.; Feldman, R. A.; Cantley, L. C. Specific Motifs Recognized by the SH2 Domains of CSK,
3BP2, FPS FES, GRB-2, HCP, SHC, SYK, and VAV. Mol. Cell. Biol. 1994, 14, 2777-2785.

17. Quintrell, N.; Lebo, R.; Varmus, H.; Bishop, J. M.; Pettenati, M. J.; Lebeau, M. M.; Diaz, M. O.; Rowley, J. D. Identification of a Human-Gene (hck) that Encodes a Protein-Tyrosine Kinase and is Expressed in Hematopoietic Cells. Mol. Cell. Biol. 1987, 7, 2267-2275.

18. Ziegler, S. F.; March, J. D.; Lewis, D. B.; Perlmutter, R. M. Novel Protein-Tyrosine Kinase Gene (hck) Preferentially Expressed in Cells of Hematopoietic Origin. Mol. Cell. Biol. 1987, 7, 2276-2285.

19. Sicheri, F.; Moarefi, I.; Kuriyan, J. Crystal Structure of the Src Family Tyrosine Kinase Hck. Nature 1997, 385, 602-609.

20. Moarefi, I.; LaFevre-Bernt, M.; Sicheri, F.; Huse, M.; Lee, C. H.; Kuriyan, J.; Miller, W. T. Activation of the Src-Family Tyrosine Kinase Hck by SH3 Domain Displacement. Nature 1997, 385, 650-653.

21. Marshall, A. G.; Wang, T. C. L.; Ricca, T. L. Tailored Excitation for Fourier-Transform Ion-Cyclotron Resonance Mass Spectrometry. J. Am. Chem. Soc. 1985, 107, 7893-7897.

22. Guan, S. H.; Marshall, A. G. Stored Waveform Inverse Fourier Transform (SWIFT) Ion Excitation in Trapped-Ion Mass Spectometry: Theory and Applications. Int. J. Mass Spect. 1996, 158, $5-37$.

23. Atherton, E.; Gait, M. J.; Sheppard, R. C.; Williams, B. Polyamide Method of Solid-Phase Peptide and Oligonucleotide Synthesis. J. Bioorg. Chem. 1979, 8, 351-370.

24. Knorr, R.; Trzeciak, A.; Bannwarth, W.; Gillessen, D. New Coupling Reagents in Peptide Chemistry. Tetrahed. Lett. 1989, 30, 1927-1930.

25. König, W; Geiger, R. N-Hydroxyverbindungen als Katalysatoren für die Aminolyse aktivierter Ester. Chem. Ber 1970, 103, 2034-2040.

26. Carpino, L. A.; Han, G. Y. 9-Fluorenylmethoxycarbonyl Amino-Protecting Group. J. Org. Chem. 1973, 37, 3404-3409.

27. Kramer, A.; Volkmer-Engert, R.; Malin, R.; Reineke, U. Schneider-Mergener J. Simultaneous Synthesis of Peptide Libraries on Single Resin and Continuous Cellulose Membrane Supports-examples for the Identification of Protein, Metal, and DNA-Binding Peptide Mixtures. J. Pept. Res. 1993, 6, 314-319.

28. Senko, M. W.; Hendrickson, C. L.; Pasa-Tolic, L.; Marto, J. A.; White, F. M.; Guan, S.; Marshall, A. G. Electrospray Ionization Fourier Transform Ion Cyclotron Resonance at 9.4 T. Rapid Commun. Mass Spectrom. 1996, 10, 1824-1828.

29. Senko, M. W.; Hendrickson, C. L.; Emmett, M. R.; Shi, S. D. H.; Marshall, A. G. External Accumulation of Ions for Enhanced Electrospray Ionization Fourier Transform Ion Cyclotron Resonance Mass Spectrometry. J. Am. Soc. Mass Spectrom. 1997, 8, 970-976.

30. Bradford, M. M. Rapid and Sensitive Method for Quantitation of Microgram Quantities of Protein Utilizing Principle of Protein-Dye Binding. Anal. Biochem. 1976, 72, 248-254.

31. Nawrocki, J. P.; Wigger, M.; Watson, C. H.; Hayes, T. W.; Senko, M. W.; Benner, S. A.; Eyler, J. R. Analysis of Combinatorial Libraries Using Electrospray Fourier Transform Ion Cyclotron Rresonance Mass Spectrometry. Rapid Commun. Mass Spectrom. 1996, 10, 1860-1864.

32. Botfield, M. C.; Green, J. SH2 and SH3 Domains: Choreographers of Multiple Signaling Pathways. Ann. Rep. Med. Chem. 1995, 30, 227-238.

33. Payne, G.; Stolz, L. A.; Pei, D.; Band, H.; Shoelson, S. E.; Walsh, C. T. The Phosphopeptide-Binding Specificity of Src Family SH2 Domains. Chem. Biol. 1994, 1, 99-105.

34. Hernandez, H; Robinson, C. V. Dynamic Protein Complexes: Insights from Mass Spectrometry. J. Biol. Chem. 2001, 276, 46685-46688. 